\title{
Bernhard Ritter*
}

\section{'Reddish Green' - Wittgenstein on Concepts and the Limits of the Empirical}

DOI 10.1515/cpt-2016-0001

Abstract: A "concept" in the sense favoured by Wittgenstein is a paradigm for a transition between parts of a notational system. A concept-determining sentence such as "There is no reddish green" registers the absence of such a transition. This suggests a plausible account of what is perceived in an experiment that was first designed by Crane and Piantanida, who claim to have induced perceptions of reddish green. I shall propose a redescription of the relevant phenomena, invoking only ordinary colour concepts. This redescription is not ruled out by anything the experimenters say. It accounts for certain peculiarities in both their descriptions and their subjects', and suggests that instead of discovering forbidden colours the experimenters introduced a new use of "-ish". Still, there is a point in speaking of "reddish green" in their context, which can be motivated by invoking what Wittgenstein calls a "physiognomy".

Keywords: arbitrariness, concept, Crane-Piantanida experiment, reddish green, Wittgenstein

What Wittgenstein means by a "concept" is subject to variation. There is, however, a dominant use of this notion, in particular in the 1940s, whose specificity is easily missed since it goes against the grain of common expectations. In the following, I shall try to state this notion as clearly as I think can be reconciled with the flexibility of Wittgenstein's use. This conception prompts the issue of conventionalism concerning what is and what is not possible - a view often associated with Wittgenstein. If sentences such as "White is lighter than black" or "There is no reddish green" reflect nothing but our linguistic practices, it seems that what is and what is not possible is made dependent on which conceptual system we adopt. A different kind of problem arises from empirical research on human vision. Crane and Piantanida were the first to claim that perception of reddish green and bluish yellow can be induced with the help of stabilised twocoloured displays (cf. Crane/Piantanida 1983). This would mean that "There is no

*Corresponding author: Bernhard Ritter, Universität Klagenfurt, Universitätsstraße 65-67, 9020 Klagenfurt, E-Mail: bernhard.ritter@aau.at 
reddish green" is really an empirical generalisation, and even a false one. I shall discuss these topics - Wittgenstein's notion of a concept, his attitude towards conceptual arbitrariness and the case of forbidden colours - in three sections.

\section{1 "Concept" in Wittgenstein}

Readers of Philosophical Investigations who make their way to what was originally referred to as "Part II" of the book, and therein to section xii on concept-formation, may not be aware of how ill-equipped they are to understand Wittgenstein's notion of a concept. Some earlier passages suggest that a concept, as he uses the term, is simply a word and its use: "We are not analysing a phenomenon (e.g. thought) but a concept (e.g. that of thinking), and therefore the use of a word." (Wittgenstein 2009, PI, § 383, cf. § 532). If a concept for Wittgenstein is just a word and its use, then concept possession can be attributed to assistant B in languagegame (2) (cf. Wittgenstein 2009, PI, § 2). This does not look as if it could be right. The only thing B does is bring builder A a block when A calls out "Block!"; bring him a pillar when he calls out "Pillar!"; bring him a slab when he calls out "Slab!"; and bring him a beam when he calls out "Beam!”. Concept possession requires more than just the possibility of describing someone's behaviour with the corresponding term. One could do this also when B were a robot. Rather, by attributing a concept of a slab to someone, we, the ascribers, attribute an understanding of "slab" to B that is at least roughly equivalent to an explanation given in our own terms. Let us say that his concept consists in (S): "that which must be handed to A when A calls out 'Slab!". This characterises the use of "slab" in language-game (2). Accordingly, if we say that this is B's concept of "slab”, we claim that there is something in his understanding of "slab" that corresponds to what we understand by that phrase. This is a minimal condition for distinguishing a case of concept possession from cases similar to that of the robot, where no correspondence of understandings is claimed. But would we say that $(\mathrm{S})$ is a concept of a slab? What might be felt to be missing is addressed in a passage of Wittgenstein's Remarks on the Foundations of Mathematics (1956):

It is not in every language-game that there occurs something that one would call a concept.

Concept is something like a picture with which one compares objects. Are there concepts in language-game (2)?

Still, it would be easy to add to it in such a way that "slab", "block" etc. became concepts. For example, by means of a technique of describing or portraying those objects. There is of course no sharp dividing line between language-games which work with concepts and others. (Wittgenstein 1956, RFM, p. 433 = MS 124, p. 192, 13 April 1944) 
What is missing in language-game (2) is a practice of describing the objects. To replace the word "slab" in (S) by "block", "pillar", or "beam", yields a characterisation of the use of these other words. The common element is: "that which must be handed to A when A calls out '...!'”. Since this is the same for each word, it is clear that it yields no description of these objects. The assistant must be able to distinguish one kind of object from the other, but for this to be possible he need not have concepts. At this point, we can say this much, that as far as empirical concepts are concerned there is an intimate connection between concepts and descriptive uses of language. "Hello" has a use in our language but is not a concept.

Wittgenstein does not say, as Frege does, that a concept generally corresponds to a grammatical predicate (cf. Frege 1892, p. 193). He states explicitly: "A concept is not essentially a predicate." (Wittgenstein 1956, RFM, p. 299). Since he does not explain much in the corresponding remark, I shall not try to broach the matter. For the following, it is sufficient to keep in mind that it must be something else that characterises a “concept” in Wittgenstein's favoured sense of the word. Contrary to what one might expect, he does not care much about how the word is used. This can be gleaned from "Part II" of the Investigations, which has been retitled more recently as Philosophy of Psychology - A Fragment. No one will find the comparison in the Fragment particularly intuitive:

Compare a concept with a style of painting ["Malweise”]. For is even our style of painting arbitrary ["willkürlich"]? Can we choose one at pleasure? (The Egyptian, for instance.) Or is it just a matter of pretty and ugly? (Wittgenstein 2009, PPF, § $367=$ PI II, xii, p. 230c) ${ }^{1}$

Wittgenstein chooses the example of Egyptian painting for its lesser degree of realism compared to, for instance, the depiction of the human body in High Renaissance art. This is suggested by an earlier manuscript passage:

Representing people (etc.) in perspective strikes us as correct compared with the Egyptian way of drawing them [“Art der Darstellung”]. Of course; after all, people don't really look like that! - But must this count as an argument? Who says I want people on paper to look the way they do in reality? (Wittgenstein 1993, PO, p. 387 = MS 119, p. 120, 15 October 1937)

Wittgenstein often appeals in this kind of context to something "we want" or what "I want". This will become important later in this article. At the moment, I only wish to note that viewing a concept as a "way" or "method" of representation is at odds with the idea that a concept is "like a picture with which one compares

1 For a subtle reading of $P P F, \S 367$, see Raatzsch 1995, p. $279 \mathrm{f}$. 
objects” (Wittgenstein 1956, RFM, p. 433). A picture with which one compares objects is not a way of making a picture: "A concept, one could say, is a method // way // of judging. Consequently, whoever invents a new way of judging, forms a concept."2 The former remark suggests a use of pictures such as those in a plant identification key, where a specimen is compared with a picture for identification. What Wittgenstein would need is a picture in a different sense. Elsewhere, he says that the "technique of multiplying establishes connexions between the concepts [of two numbers]". The multiplication is "a picture of this transition" (Wittgenstein 1956, RFM, p. 297). He then goes on to suggest to "conceive the written multiplication as one picture", and thus as one concept (Wittgenstein 1956, RFM, p. 298). Wittgenstein associates the notion of a concept to that of a transition for which the concept is a paradigm. Accordingly, if a concept is a picture, it is a picture of an operation; of how we are to proceed.

How is this to be applied to the concept of a slab? It is important to note that an ostensive definition, or ostensive explanation, can be made explicit by using the phrase "is called ' $X$ "”. Thus, if "This is a slab" is used as an ostensive definition, it can be rendered as: "This $\rightarrow$ (building element) is called 'slab'." The specifier "building element" shows "what place in language, in grammar, we assign to the word" (Wittgenstein 2009, PI, § 29). The relevant transition is from "this $\rightarrow$ building element" (where the arrow stands for a pointing gesture) to "slab" - a general name for that kind of building element. An ostensive explanation does not require that the word to be explained should already be in use. An ostensive explanation is not the same as giving an example:" "This building element, for instance, is a slab." It would be difficult to say this if "slab" has not yet been introduced. This is crucial to understand the way in which an ostensive definition is a picture. The difference is more apparent in the case of colour. One cannot say: "This $\rightarrow$ (colour), for instance, is called 'red'." For we do not predicate "red" of the object before us, nor do we predicate "red" of a particular hue of red. For the latter, one would have to say: "This $\rightarrow$ (colour), for instance, is a red." But if the sample to which we are pointing is simply red, as paradigmatically red as red can be, it would be wrong to say that it is " $a$ red". For red is not a hue of red. Moreover, the phrase "is called ' $X$ "' is not a sign for predication. This is particularly clear in cases were " $\mathrm{X}$ " is introduced as a new word: " $\mathrm{X}$ ' is to be used to apply to such things." In an ostensive definition, the object pointed to

2 MS 127, p. 159f., between 4 March and 7 April 1944, my translation. As is common, I use a double slash to indicate a variant in Wittgenstein's Nachlass.

3 To show that this is Wittgenstein's view would require some space, which I prefer to save. However, see MS 150, p. 75 (1935-36) and NFL, p. 277 = MS 151, p. 12 (1936), while MS 155, p. 67v70r (1931) is admittedly ambiguous. 
plays a similar role to that of a triangle drawn on the black board in a geometrical demonstration. By saying, "This (building element) is called 'slab", while pointing to the corresponding element, I am exhibiting how "slab" is to be applied. This performance is a paradigm or picture of how it is to be used, or what can be done with it in the language.

Let us pause for a moment to see where we have got. I do not mean to deny that there are cases in which the word "concept" in Wittgenstein can be explained by saying that a concept is a particular word and a way, or ways, of using it. As has been seen, Wittgenstein is undecided whether also to call the symbolic expressions between which a transition takes place "concepts". He admits that the word "concept" is vague, and he would be the last to make an attempt at regimentation (cf. Wittgenstein 1956, RFM, p. 412, p. 433). At the same time, there is a more determinate concept of "concept" in Wittgenstein. A concept in this sense is not only (1) a way or ways of using a word but (2) is also bound up with a method, or technique, of description. It is (3) a picture, or paradigm, of a transition between two symbolic expressions in a system. ${ }^{4}$ To this, I wish to add: (4) a concept is characterised by concept-determining sentences ("begriffsbestimmende Sätze"), ${ }^{5}$ such as "There is no such thing as a regular biangle", "There is no such thing as reddish green", or "White is lighter than black" (cf. Wittgenstein 1980b, RPP II § $421 \mathrm{f}$; Wittgenstein 1956, RFM, p. 75).

\section{Wittgenstein on Conceptual Arbitrariness}

It is tempting to conceive of this kind of sentences as modal claims about structural features of the world or of experience (cf. Suarez/Nida-Rümelin 2009, p. 346-355). This view finds a characteristic expression in Bertrand Russell's "The Limits of Empiricism", which is commonly taken to have stimulated Wittgenstein's treatment of the matter. "In looking at the rainbow", Russell writes,

we can perceive that blue and green are more similar than blue and yellow; moreover, it is evident that this is not merely a relation between three particular patches of colour, but between their shades, which are universals. (...) [K]nowledge [concerning universals] may be exemplified in other sensible facts, and (...) gives us hypothetical knowledge concerning such facts. That is to say, having carefully observed blue, green, and yellow in one sensible

4 For a discussion of the notion of a "system" in Wittgenstein, see Schulte 2014.

5 The difficulty of translating Wittgenstein's notion of a Satz has often been noted. I translate "begriffsbestimmender Satz" conservatively as "concept-determining sentence", which accordingly should be taken as a quasi-technical term. 
fact, we can say: Wherever these shades may occur, green will be intermediate in colour between blue and yellow. (Russell 1936, p. 140)

A statement like "Yellow is more like green than it is like blue" is entirely general and can be read off from present sense-data, according to Russell. In his view, the relationships between the shades of colour are also universals. Propositions about instantiations of green, blue, and yellow are only known hypothetically, whereas knowledge about universals, once acquired, is indefeasible. ${ }^{6}$

Russell's title, "The Limits of Empiricism", refers to the limitations of a theory of knowledge that starts off with raw sense-data. Russell argues that what is commonly considered as empirical knowledge would become impossible without a particular set of non-empiricist principles, such as "facts about universals can be immediately perceived" (Russell 1936, p. 148). In Wittgenstein's Remarks on the Foundations of Mathematics and associated manuscripts, the topic of sensedata is never brought up. What he calls "the empirical" is conceived of in terms of propositions which can be meaningfully denied (cf. Wittgenstein 1956, RFM, p. 225f., p. 332). Still, Wittgenstein is certainly reacting to Russell when he writes:

The limit of the empirical - is concept-formation. (Wittgenstein 1956, RFM, p. $237=$ MS 125, p. 41v, February-March 1942)

The limits of the empirical are not assumptions unguaranteed, or intuitively known to be correct: they are ways [“Arten und Weisen"] in which we make comparisons and in which we act. (Wittgenstein 1956, RFM, p. 387, transl. alt. = MS 124, p. 90, 2 July 1941)

I take the expression "Arten und Weisen" to cohere with what has been suggested in the first section. It is not a set phrase like "Art und Weise" in the singular. That Wittgenstein thinks of concepts when he uses this expression is indicated by the first quotation, which mentions concept-formation.

Let us see how Wittgenstein accounts for the type of sentences Russell mentions. Wittgenstein says that one has a strong sense of stating something about the nature of black and white when uttering, "White is lighter than black". He asks:

Is it not like this: the picture of a black and a white patch

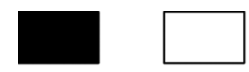

6 Russell does not draw this distinction in his 1913 manuscript of Theory of Knowledge, which Wittgenstein is known to have read. But the view that we can know by acquaintance that two things A and B are similar is also maintained there (cf. Russell 1913, p. 9, p. 148 f., p. 154f.). 
serves us simultaneously as a paradigm of what we understand by "lighter" and "darker" and as a paradigm for "white" and for "black". Now darkness 'is part of' black inasmuch as they are both represented by this patch. It is dark by being black. - But to put it better: it is called "black" and hence in our language "dark" too. (Wittgenstein 1956, RFM, p. $75=$ MS 117, p. 34f., 1937, and MS 118, 28 August 1937)

In an ostensive explanation of "darker" and "lighter", the same samples can be used as in an ostensive explanation of "black" and "white"; these samples can also be used in a description. The concepts in the sense with which we are concerned, are the transitions that can be introduced by reference to the samples; the transition between the term "this $\rightarrow$ colour" and "black", between "black" and "darker", and "white" and "lighter".

A mathematical example may help to make this clearer. Let us suppose that we want to prove $(a+b)^{2}=a^{2}+2 a b+b^{2}$ and that our proof procedure is exhausted by the operation of expanding (apart from some simple ways of associating number signs). Thus, I can prove that $(a+b)^{2}$ equals $a^{2}+2 a b+b^{2}$ by expanding in the manner indicated below by the connecting lines. Drawing these lines can be imagined to be an essential part of the proof procedure:

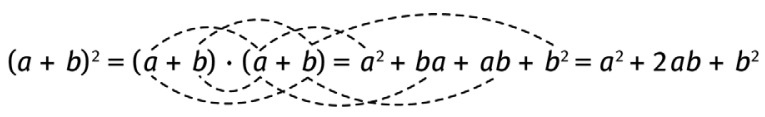

If we represent this geometrically:

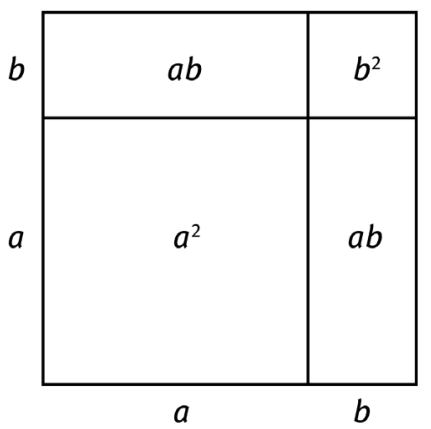

we can see that we have a paradigm here, very similar to the black and the white squares used in Wittgenstein. The same square surface area is simultaneously a paradigm for $(a+b)^{2}$ and for $a^{2}+2 a b+b^{2}$. A corresponding figure could be drawn for any quadratic equation of which one side is the expansion or factorisation of the other, respectively. Doing this, just as saying that white is lighter than black, is not stating a fact. The signs are used to manifest our understanding of them by demonstrating a transition from one part of a linguistic or mathematical whole to 
another. This operation, or the performing of it, is taken as "equivalent with the picture of the transition itself” (Wittgenstein 1956, RFM, p. 434). It is a picture of what we can do; of how we can move around in the system.

If sentences such as "White is lighter than black" or "There is no reddish green" are only concerned with our practice in the way indicated, it seems that what is and what is not possible will depend entirely on the structure we decide to lay down for our symbolic practices (cf. Wittgenstein 2009, PI, § 520). It is true that Wittgenstein rejects the idea that there is something in the descriptiveness of a given way of representing things that forces rational beings to prefer it to others. He precisely does not say "that certain concepts are absolutely the correct ones" (Wittgenstein 2009, PPF, § 366 = PI II: xii, p. 230b). However, nor does he say that our systems of representation are arbitrary in an unqualified way (cf. Wittgenstein 2009, PI, § 497):

We have a colour system as we have a number system.

Do the systems reside in our nature or in the nature of things? How are we to put it? Not in the nature of numbers or colours. (Wittgenstein 1980b, RPP II, § 426)

Then is there something arbitrary about this system? Yes and no. It is akin both to what is arbitrary and to what is non-arbitrary. (Wittgenstein 1980b, RPP II, § 427) ${ }^{7}$

To say "It is akin both to what is arbitrary and to what is non-arbitrary" is a nonanswer that needs to be linked up with other texts for it to be of any help. I want to present two ways in which this has been done and say which one I prefer.

According to Michael Forster, what Wittgenstein says in the quotation above, is that there is a sense in which grammar is arbitrary and a sense in which it is not (cf. Forster 2004, p. 2). Although this is not exactly what Wittgenstein says here, there are passages from the early 1930s where he expresses himself in that way (cf. Wittgenstein 1980a, LWL, p. 49). Accordingly, Forster conceives the task as one of spelling out the senses in which grammar is on the one hand arbitrary and on the other non-arbitrary. Grammar's arbitrariness, Forster argues, comprises two components: non-justifiability by reference to facts and what he calls Wittgenstein's “diversity thesis” (cf. Forster 2004, p. 21-65). The diversity thesis says that "for all grammatical principles in all areas of the grammar which governs our 'true-false games,' alternative but in some degree similar grammatical principles (...) either have actually been used or are at least possible and conceivable" (Forster 2004, p. 46f.). These alternatives are "rivals" in the sense of involving “conceptual incommensurability” (Forster 2004, p. 204, n.1). Grammar is non-

7 These two remarks are first drafted in MS 137, p. 6a-b, 5 February 1948. 
arbitrary insofar as our nature, the social practices and traditions in which we are brought up, as well as the requirement of applicability, place constraints on our choice (cf. Forster 2004, p. 66-70).

Forster refers to passages from all the later published writings of Wittgenstein and construes them as expressing one view on the arbitrariness of grammar. He does not claim that this view is consistent, but even reading these texts as if they were meant to express one view is not an innocent decision (cf. Forster 2004, p. 193-195, n. 5). There is no room for change or development in Forster's interpretation, not even where this is obvious and relevant for his concerns, as is the case with the extension of the sense in which Wittgenstein talks of "grammar" or "logic" in his last writings. ${ }^{8}$ Apart from that, I think that he is basically right in what he says about non-justifiability and arbitrariness in Wittgenstein (cf. Forster 2004, p. 42f.). His attribution of a "diversity cum incommensurability" thesis to Wittgenstein, on the other hand, is little convincing. Much of what Wittgenstein says about reddish green is difficult to reconcile with such an attribution. I shall turn to this topic in the next section.

A very different approach can be seen at work in two recent papers by Joachim Schulte. Schulte focusses on the manuscript versions of partly published material from the 1940s, which is when Wittgenstein examined the notion of a concept most intensely (cf. Schulte 2010, p. 128). The quotation given above (Wittgenstein 1980b, RPP II, § 426f.) is central to the more recent paper. Schulte suggests reading Wittgenstein's non-answer as indicating an unwillingness to accept that either our system of colours depends on our nature and is arbitrary, or depends on the nature of colours and is non-arbitrary. The reason, Schulte argues, is that "[Wittgenstein] would not want our nature and the nature of things to enter the equation separately" (Schulte 2014, p. 31). Schulte refers to the following Nachlass passage for clarification:

It is obvious at first blush that we do not want to acknowledge a colour intermediate between // of // red \& green. (And it is irrelevant here whether people have always found this obvious or only after experience \& education.)

"This is the way in which I want to put things together", one could say. (Wittgenstein 2001, MS 137, p. 6b-7a, 5 February 1948, transl. B. R.)

Schulte comments that, "saying that I want to put them together in this particular way serves to highlight (...) that our nature, our nature as human beings, should

8 Compare Wittgenstein 2009, PI, § 90, § 199, § 251, § 295, § 360 with OC § 53, § 57-60, § 96-99, § 136, § 319-321, § 342, § $401 \mathrm{f}$. 
be taken into account when it comes to considering our system" (Schulte 2014, p. 23). I take this to emphasise both our role as creators of the system of colour terms and the fact that this involves a will which is not abstract, but is in itself expressive of our nature.

Schulte's interpretation has several elements, of which I want to mention two more. The first is that what requires behaviour with a structure at all is solutions of problems (cf. Schulte 2014, p. 25-28). It is possible to express the problem, for example, of how a given colour can be produced by mixing other colours algebraically. The second, crucial one, is that life and language get unified into a structured whole in language-games, which cannot be done in arbitrarily many ways. As Schulte translates from a notebook entry of 1 July 1948: "By pointing out the language-game one shows the connection between language and life. That is (...) the way language is interwoven with other things that happen in life." This can be supported by a passage from Wittgenstein's unpublished Lectures on Belief, from Easter Term 1940. Wittgenstein answers the question in very much the way Schulte suggests: that if one were to mention anything from whose "nature" the categories that we draw depend, one could say that they depend on the nature of our lives (cf. Wittgenstein forthcoming, WCL, Belief Lecture 7, 21 May 1940). "Life" is the title under which our nature and the nature of things enter the equation together. Schulte's paper offers a very balanced interpretation of Wittgenstein on the arbitrariness of grammar. It manages to integrate many different themes in Wittgenstein into an overall conception for which "conventionalism" is, at best, a poor description.

\section{3 "Reddish Green" - the Case of Forbidden Colours}

Attributing a "diversity cum incommensurability" thesis to Wittgenstein is difficult to align with his discussion of "reddish green" and "bluish yellow", even on the rather vague understanding of the diversity thesis provided by Forster (cf. Forster 2004, p. 203f., n. 1). What I have in mind are passages like the following:

But even if there were also people for whom it was natural to use the expressions "reddishgreen" or "yellowish-blue" in a consistent manner and who perhaps also exhibit abilities which we lack, we would still not be forced to recognize that they see colours which we do not see. There is, after all, no commonly accepted criterion for what is a colour, unless it is one of our colours. (Wittgenstein 1979, RC I, § 14 = MS 176, p. 5r, early 1951)

9 Wittgenstein 2001, MS 137, p. 61b, translated in Schulte 2014, p. 31. 
Of course, in order for there to be "colours which we do not see", there would have to be a way to establish that what these people perceive are really colours. Accordingly, although we would fail to capture what they seem to discriminate, we would need to have a basic understanding of what they say in order to be able to tell that the words we do not understand are colour words. The point I take Wittgenstein to be making is that these are irreconcilable requirements. Whatever has a tendency to show that people different from us recognise "colours which we do not see", will at the same time have a tendency to show that what they perceive are not really "colours". 10

The case of "forbidden colours" presents itself as an empirically founded case for incommensurability. Ordinary human beings are said to have colour perceptions that require a description which contradicts our ordinary colour concepts (cf. Billock et al. 2001, p. 2398). It is claimed that it is possible to perceive reddish green and bluish yellow under the following special conditions. Colour perception depends on small involuntary eye movements. These eye movements can be recorded with an eye tracker. Using the data of the eye tracker, a strip on a coloured display can be moved synchronically to the eye movements of a subject, while leaving the surroundings of the strip unmoving. To use the technical term, the strip is "stabilised". This provokes the effect that the coloured strip is first seen to "disappear", as this is described by subjects. Then, the colours surrounding the strip are "filled in", as many experimenters claim (cf. Billock/Tsou 2010, p. 73). An interesting question is what happens when the colours surrounding the strip are red and green. Crane and Piantanida, who first conducted this experiment, describe their results in the following way:

\begin{abstract}
Some dyadic color names (such as reddish green and bluish yellow) describe colors that are not normally realizable. By stabilizing the retinal image of the boundary between a pair of red and green stripes (or a pair of yellow and blue stripes) but not their outer edges, however, the entire region can be perceived simultaneously as both red and green (or yellow and blue). (Crane/Piantanida 1983, p. 1078)
\end{abstract}

I first want to note that it is not accurate to say that perceiving something to be of an "-ish" colour is the same as perceiving a surface as having two colours at the same time. When something is seen to be bluish green, for example, it is not blue and green at the same time. Something is either blue or green or bluish green. When a surface is bluish green, it is of one colour of which blue and green are

10 Cf. "Can we imagine that other people have other colour concepts? - The question is: should we call other concepts colour concepts?” (Wittgenstein 1992, LW II, p. 44 = MS 169, p. 72r, 1949, first half). There is some degree of undecidedness in Wittgenstein on this point, see Wittgenstein 1979, RC III, § 42 and § 123f. = MS 173, p. 11r-v and 28r-v, March-April 1950 
seen to be the components. Bluish green is not like a chemical solution - air, for example - but like a chemical compound - pure water, $\mathrm{H}_{2} \mathrm{O}$. Accordingly, for something to be reddish green, it is not sufficient that red and green be dispersed over the same surface, since this may be a case in which both colours are present on the surface the one beside the other. Rather, there would have to be a new colour quality in which both elements are perceived. By itself, this inaccuracy of expression does not prove anything against Crane and Piantanida. It may simply be an insignificant slip, which is likely to occur given the unusual phenomena they have to deal with.

However, in view of their formulation, the authors could just as well have claimed that two colours can be seen in one and the same place, which is neutral with regard to the question of intermediate colours. Making this claim, which they do not, would of course preclude the further claim that their subjects have seen intermediate colours where ordinarily there is no place for them. Thus, in order to arrive at their desired conclusion, the authors have to accept as a principle that two colours cannot be in one and the same place. More explicitly: "If $A$ and $B$ are different colours, they cannot be seen in the same place at the same time. If they are seen in the same place at the same time, they are not two colours, but one. The only way for red and green to be perceived as being present in one colour is to perceive reddish green."

Surprisingly, none of the experimenters give a record of what their subjects actually said, as might be expected from an empirical study. Billock, Gleason, and Tsou write: "Our subjects (...) were tongue-tied in their descriptions of these colors, using terms like 'green with a red sheen,' or 'red with green highlights'.” (Billock et al. 2001, p. 2398) Using these terms for what; answering which question? Apparently, they did not use the term "reddish green". If what they said was that the strip was "green with a red sheen" or "red with green highlights", rather than the colour of the strip, we certainly need to be told. The reactions of Crane's and Piantanida's subjects are reported even more summarily: “Although most reported that (...) the colour was simultaneously red and green, some observers indicated that although they were aware that what they were viewing was a color (...), they were unable to name or describe the color." (Crane/Piantanida1983, p. 1079). Also these subjects did not use the expression "reddish green", although they seem to have talked of perceiving one colour, which is not the same as saying that an "entire region can be perceived simultaneously as both red and green (or yellow and blue)" (Crane/Piantanida 1983, p. 1078). Since the experimenters think that these differences do not matter, I should rather be given a full record of what their subjects actually said. The experimenters themselves, naturally, prefer the more exciting interpretation of their results. Trying to achieve exciting results was also part of their original motivation, as Billock and Tsou readily admit: "Like 
engineers, many scientists also have a secret love for destructive testing - the more catastrophic the failure, the better. Human vision researchers avoid irreversible failures (and lawsuits) but find reversible failures fascinating and instructive (...).” (Billock/Tsou 2010, p. 72)

I emphasised that what the experimenters would have to show is that they induced the perception of a new colour quality intermediate between red and green, corresponding to a chemical compound rather than to a chemical solution. An "intermediary colour”, or Zwischenfarbe as Wittgenstein calls it, is an “-ish" colour. As this suffix is ordinarily used, it applies to the colour pairs green-blue, blue-red, red-yellow, and yellow-green, as well as to black and white in combination with all four primary colours (assuming that there are four). Concerning the latter, one would prefer to speak of a dark or a light colour instead of a "blackish" or a "whitish" colour. ${ }^{11}$ This is what impressed Wittgenstein about the colour octahedron; that it appears to summarise our use of "-ish" as applied to colours (cf. Lugg 2008, p. 156-158). The use of “-ish” is also what coheres better with assuming four primary colours instead of three, although all colours can be mixed by using only yellow, red and blue. We do not perceive a light green as "bluish", for example, although we know that it can be made of blue and yellow.

I think this is why Wittgenstein, in his Lectures on the Foundations of Mathematics, compares mixing colours - not paints - with multiplication (cf. Wittgenstein 1976, LFM, p. 234). The number 10, for instance, shares no important features with 7 and 3, of which it is the sum. On the other hand, we see immediately whether a given number is a multiple of 2,5 , or 10 , although not whether it is a multiple of any number. Similarly, we can immediately tell which colours are involved in a yellow that tends towards orange, or a blue that tends towards violet, and use the suffix "-ish" to mark the predominance of one colour relative to another, as in "bluish green", or a tinge of a colour in another, as in "reddish yellow". This is contrary to what might be suggested by saying that "[s]ome dyadic

11 In fact, these are not just notational variants. Wittgenstein is reluctant to admit that there could be luminous grey ("leuchtendes Grau") (cf. Wittgenstein 1979, RC I, § 40). However, a luminous grey can be produced, for instance, in watercolours by using only pure yellow, red and blue. Each colour is laid on the paper in a transparent layer, beginning with yellow. They are "mixed" on the paper, which is done by adding the next layer only after the preceding one has dried, and with diminishing brightness, so as to outweigh the greater darkness of red and blue respectively. If the layers are approximately equal in darkness value, the result will be a peculiar kind of grey that is markedly different from any grey that is made with black, and which by comparison merits the description "luminous". Elsewhere Wittgenstein admits that "dark" is not equivalent to "blackish": "Why is it that a dark yellow does not have to be perceived as 'blackish', even if we call it dark?” (Wittgenstein 1979, RC III, § 106). But if this is so, also grey need not be a blackish colour (cf. Wittgenstein 1979, RC I, § 55). 
color names (such as reddish green and bluish yellow) describe colors that are not normally realizable" (Crane/Piantanida 1983, p. 1078). There are colours that result from mixing red and green on the one hand and blue and yellow on the other, namely: brown and green. The point is rather that what we call "brown" allows no transition to "reddish green" as is allowed, for example, from "black" to "dark". Brown is not a hue of red, and a brown that is mixed with less red is not in itself more greenish. Similarly, green is not a hue of blue, and a green that is mixed with less blue is not in itself more yellowish.

A major obstacle for assessing the Crane-Piantanida experiment is that only someone who participated in the experiment appears to be competent to judge matters. This obstacle is a major one but is less insurmountable than it may seem, for there are much simpler experiments which produce essentially the same effects. I find that I can achieve all of the important effects that are listed by Billock and Tsou as well as Suarez and Nida-Rümelin simply by crossing my eyes before a display that is half red and half green so as to make them overlap - that is, judged from their descriptions (cf. Billock/Tsou 2010, p. 75). Accordingly, I can experience something that one may want to call "a homogeneous colour phenomenally composed of red and green", "a gradient colour that runs from red on one side to green on the other", as well as a "transparency phenomenon" of seeing one colour arranged in a plane behind the other and seeing "one through the other" (cf. Suarez/Nida-Rümelin 2009, p. 358-360). The physiology in the "simple" experiment is, of course, very different. However, approaches have already been suggested to make this kind of phenomena examinable under ordinary circumstances.

Livitz and collaborators, for instance, try to exploit two illusory colour experiences to give a similar effect as Crane and Piantanida. One is the illusion of seeing a neutral surface in a colour complementary to its surrounding colour; the other is the illusion of "completing" a figure in the same colour in which it is outlined in neutral surroundings. The authors claim that these illusory experiences can be combined so as to yield an illusory reddish-green experience. The idea is that this might be possible when the perception induced by the first illusion is one of green, and the perception induced by the second illusion is one of red. Their Figure 1(c) induces the first illusion, that of seeing an illusory complementary colour. ${ }^{12} \mathrm{~A}$ major weakness in their approach becomes apparent when they say that "the black diamond in Fig. 1(c) appears greenish". For the figure is not greenish in an unqualified way. If one looks at the diamond figure up close, it appears uniformly black (cf. Livitz et al. 2011, p. 2, p. 4). It is only when moving one's eyes or looking at the figure from some distance that it appears greenish or with a greenish halo.

12 Readers are requested to check the figures in Livitz et al. 2011, which won’t be reproduced here. 
Evidently, this is not what happens with ordinary objects that are bluish green or reddish yellow. The black diamond figure appears greenish only when at the same time there is indeterminacy about where exactly the colour appears. Now, if it is indeterminate in this case, it is also indeterminate in the cases which they present as examples of reddish green! I do not find these examples very convincing, but even if they were more convincing, they would display the same kind of indeterminacy as Figure 1(c). I shall argue that something similar is true in the experiment with stabilised two-coloured displays.

My main reason for thinking that the effects induced by the "simple" experiment are the same as those in the experiment with stabilised two-coloured displays, is that Billock and Tsou themselves recommend the "simple" experiment:

Try staring intently at these pairs of rectangles [shown on page 77 of the journal], allowing your eyes to go cross-eyed so that the red and green areas overlap (...) Some people get glimpses of forbidden reddish green as the patches change colour, but the method is much less reliable than using equiluminant stabilized images. (Billock/Tsou 2010, p. 77)

Tsou is red-green colour-blind and has to be counted out, but Billock participated as a subject in the experiment with stabilised two-coloured displays and is certainly in a good position to tell whether the effects are the same (cf. Billock/ Tsou 2010, p. 74). Moreover, if the effects were to be fundamentally different, this would be a remarkable fact in itself, and one which would require explanation.

My argument is not a direct objection to their findings. It proceeds essentially by an alternative description - one that invokes only ordinary colour concepts. In order to maintain that they have achieved their desired result, the experimenters would have to exclude this redescription as the more accurate one. This redescription runs as follows. In the "simple" experiment, and by extrapolation in the Crane-Piantanida experiment too, one is experiencing a surface where red and green appear to be present simultaneously. For instance, the surface runs from green on the one end to red on the other. However, I do not see a new colour quality between red and green. What happens is that in between the red and the green extremes, which are spatially separated, the predominance of red on the surface gradually gives way to the predominance of green, entirely quantitatively. Red and green are seen to co-exist, without being able to say with certainty whether a single spot is really red and green at the same time, as the colours are too finely dispersed and there is no "examining from close up". The colours are not "multiplied" with one another, as Wittgenstein would say; there is no new result (cf. Wittgenstein 1976, LFM, p. 234).

This accounts for the fact why in spite of the greatly emphasised extraordinariness of the experience, the subjects have no difficulties in recognising that the colours are red and green. To reply that this is because they know it from having 
seen the two-coloured display at the beginning of the experiment would, of course, be self-refuting; to reply that at least some of them are tongue-tied shows nothing. The subjects perceive red and green in the apparent mixture colour "as clear and as compelling as the red and blue components of a purple” (Billock et al. 2001, p. 2399). I suggest that it is even more compelling than red and blue in a purple, since in fact two colours are seen. My redescription also accounts for the fact why the subjects in the Crane-Piantanida experiment do not use "-ish" but prefer "and" and "with" formulations: "green with a red sheen", "red with green highlights", "both red and green". In fact, Crane and Piantanida themselves described it very accurately as "perceiving something simultaneously as both red and green (or yellow and blue)" (Crane/Piantanida 1983, p. 1078). This is the fundamental description of what is perceived in the experiment. It is a description of a surface, not of a colour, and it does not support the conceptual move to "reddish green" or "bluish yellow". This transition cannot be treated as self-evident, since statements like "a surface that is perceived simultaneously as both blue and green is bluish green" are not commonly made. For "-ish" to be applied as it ordinarily is, there would have to be one intermediary colour, while what is seen in the experiment is better described as two colours, finely dispersed over a surface. Thus, rather than discovering forbidden colours, the experimenters have introduced a new use of "-ish".

One may want to say now that what they call "reddish green" cannot possibly be a genuine mixture colour, since we know perfectly well what it would be, namely: brown. Thus, if what they say were to be correct, there would have to be two distinct colour compounds for red and green; one that is seen as reddish green and one that is not. However, the same process applied to red and green on different occasions cannot yield different results. If the result is not brown, the process cannot be one of mixing colours. Although this is a petitio, it strikes me as illuminating. If using stabilised two-coloured displays in the way described is a method of mixing colours, one would have to suppose that one and the same operation applied to the same two colours can have two different results. Curiously, the experimenters say nothing about using colour pairs such as red and yellow and whether this would result in a perception of orange, or whether their subjects can be trained to see brown when red and green is used. This may well be likely, since it is possible in the "simple" experiment, especially when the red and green areas overlap only slightly. ${ }^{13}$

13 Neuroscientists Po-Jang Hsieh and Peter Ulric Tse have actually argued that what is seen in the Crane-Piantanida experiment are brownish hues, when red and green are used (cf. Hsieh/Tse 2006, p. 2257). 
Nevertheless, there is a point in describing the phenomenon in question as "reddish green" (although in some respect "red-green" would have been more accurate). It meshes with other things we say. I mentioned the gestalt effect of seeing the colours arranged in spatially separated planes and seeing one through the other, which can also be induced in the "simple" experiment. If one really were to see a surface that has one colour through a transparent surface of another colour, one would see the area where they intersect in a genuine mixture colour. In the experiment, one is not really seeing one surface through the other, but the experience is sufficiently similar to that. Moreover, there are things which people are prepared to call "reddish green". Andrew Lugg mentions red-speckled autumn leaves (cf. Lugg 2008, p. 179). Wittgenstein gives the example of "holly leaves which are red at one point and green at another and at a point in between they are a sort of iridescent black", and continues: "I've often thought that if I had to call something reddish-green it would be that." (Wittgenstein 1976, LFM, p. 244)

It is important to gather the change in direction involved in these statements. Wittgenstein does not mean to say that his imagined holly leaves are reddish green in the same sense in which a leaf can be bluish green. Every spot would either be red or green, which could be checked by examining the leaf from close up. He means to invent for "reddish green" what he calls elsewhere a "physiognomy", something characteristic that stands out among other possible arrangements of colours and shapes (cf. Wittgenstein 1956, RFM, p. 67; Wittgenstein 1980b, RPP II, § 68; Schulte 2010, p. 133). In a notebook entry from 4 February 1948, Wittgenstein writes: “'A concept is not just a technique, but also a physiognomy.' Does 'physiognomy' mean here 'something memorable'? Something that can become a good acquaintance? The centre of a host of associations? -" (Wittgenstein 2001, MS 137, p. 4b, transl. B. R.) I suggest that what is called "reddish green" in the Crane-Piantanida experiment has a physiognomy in this sense. It is something striking and memorable, in the way Livitz' reddish green is not, and it is connected with common associations and other things we say. Thus, although what the experimenters succeed to show falls short of their original claim, they did something respectable: they formed a new concept. ${ }^{14}$

14 Thanks are due to Richard Raatzsch for critical comments on an earlier version of this paper, entitled “'Reddish Green' - Wittgenstein on Concepts and the Limits of Arbitrariness”, read at the workshop Wittgenstein on Concept-Formation and the Limits of the Empirical at the WU Vienna on 16 December 2011, and to Andrew Lugg for a sustained correspondence on Wittgenstein and the case of forbidden colours. 


\section{Bibliography}

Billock, Vincent A./Gerald A. Gleason/Brian H. Tsou (2001): "Perception of forbidden colors in retinally stabilized equiluminant images: an indication of softwired cortical color opponency?". In: Journal of the Optical Society of America, Vol. 18, No. 10, pp. 2398-2403.

Billock, Vincent A./Brian H. Tsou (2010): "Seeing Forbidden Colours". In: Scientific American, Vol. 302, No. 2, pp. 72-77.

Crane, Hewitt D./Thomas P. Piantanida (1983): “On Seeing Reddish Green and Yellowish Blue”. In: Science, New Series, Vol. 221, No. 4615, pp. 1078-1080.

Forster, Michael N. (2004): Wittgenstein on the Arbitrariness of Grammar. Princeton, Oxford: Princeton University Press.

Frege, Gottlob (1892): “Über Begriff und Gegenstand”. In: Vierteljahresschrift für wissenschaftliche Philosophie, Vol. 16, pp. 192-205.

Hsieh, Po-Jang/Peter Ulric Tse (2006): “Illusory colour mixing upon perceptual fading and fillingin does not result in 'forbidden colors'." In: Vision Research, Vol. 46, pp. 2251-2258.

Livitz, Gennady/Arash Yazdanbakhsh/Rhea T. Eskew, Jr./Ennio Mingolla (2011): "Perceiving Opponent Hues in Color Induction Displays”. In: Seeing and Perceiving, Vol. 24, pp. 1-17.

Lugg, Andrew (2010): “Wittgenstein on Reddish Green”. In: Antonio Marques/Nuno Venturinha (Eds.): Wittgenstein on Forms of Life and the Nature of Experience. Bern: Peter Lang, pp. 155-181.

Raatzsch, Richard (1995): “Begriffsbildung und Naturtatsachen”. In: Eike von Savigny (Ed.). Wittgenstein über die Seele. Frankfurt am Main: Suhrkamp, pp. 268-280.

Russell, Bertrand (1936): “The Limits of Empiricism”. In: Proceedings of the Aristotelian Society, New Series, Vol. XXXVI, pp. 131-150.

Russell, Bertrand (1984 [1913]): Theory of Knowledge: The 1913 Manuscript. Collected Papers of Bertrand Russell, Vol. 7. London: Allen \& Unwin.

Schulte, Joachim (2010): “Concepts and Concept-Formation”. In: Nuno Venturinha (Ed.): Wittgenstein After his Nachlass. Basingstoke, New York: Palgrave Macmillan, pp. 128-142.

Schulte, Joachim (2014): "We Have a Colour System as We Have a Number System”. In: Frederik A. Gierlinger/Štefan Riegelnik (Eds.): Wittgenstein on Colour. Berlin: De Gruyter, pp. 21-32.

Suarez, Juan/Martine Nida-Rümelin (2009): “Reddish Green: A Challenge for Modal Claims About Phenomenal Structure”. In: Philosophy and Phenomenological Research, Vol. 78, No. 2, pp. 346-391.

Wittgenstein, Ludwig (1956): Remarks on the Foundations of Mathematics. (RFM). Georg H. von Wright/Rush Rhees/G. E. M. Anscombe (Eds.). Transl. by G. E. M. Anscombe. Oxford: Blackwell, 1956; 2nd edition, 1967; 3rd edition, 1978.

Wittgenstein, Ludwig (1974 [1969]): Über Gewissheit - On Certainty. (OC). G. E. M. Anscombe (Ed. and transl.)/D. Paul (transl.)/Georg H. von Wright (Ed.). Malden, MA: Blackwell.

Wittgenstein, Ludwig (1976 [1939]): Lectures on the Foundations of Mathematics. (LFM). Cora Diamond (Ed.). Hassocks: The Harvester Press.

Wittgenstein, Ludwig (1979): Bemerkungen über Farben - Remarks on Colour. (RC).

G. E. M. Anscombe (Ed. and transl.). Oxford: Blackwell.

Wittgenstein, Ludwig (1980a): Lectures, Cambridge, 1930-1932. (LWL). Desmond Lee (Ed.). Oxford: Blackwell.

Wittgenstein, Ludwig (1980b): Remarks on the Philosophy of Psychology. Vol. 2. (RPP II). G. E. M. Anscombe/Georg H. von Wright (Eds.). Transl. by G. E. M. Anscombe. Oxford: Blackwell. 
Wittgenstein, Ludwig (1992): Last Writings on the Philosophy of Psychology: The Inner and the Outer. Vol. 2. (LWII). Georg H. von Wright/Heikki Nyman (Eds.). Transl. by C. G. Luckhardt/M. A. E. Aue. Malden, MA: Blackwell.

Wittgenstein, Ludwig (1993): Philosophical Occasions 1912-1951. (PO). James C. Klagge/Alfred Nordmann (Eds.). Indianapolis and Cambridge: Hackett Publishing.

Wittgenstein, Ludwig (1993): “Notes for Lectures on 'Private Experience' and 'Sense Data”. (NFL). In: Philosophical Occasions 1912-1951, pp. 200-288.

Wittgenstein, Ludwig (2001): Nachlass: The Bergen Electronic Edition. (MS). London, New York: Oxford University Press.

Wittgenstein, Ludwig (2009): Philosophical Investigations. (PI). Revised 4th edition. Peter M. S. Hacker/Joachim Schulte (Eds. and transl.). Transl. by G. E. M. Anscombe. Malden, MA: Wiley-Blackwell.

Wittgenstein, Ludwig (2009): Philosophy of Psychology - A Fragment. (PPF= PI II). In: Philosophical Investigations, pp. 182-243.

Wittgenstein, Ludwig (forthcoming): The Whewell's Court Lectures, Cambridge, 1938-1941. (WCL). Volker A. Munz/Bernhard Ritter (Eds.). Chichester: Wiley-Blackwell. 